\title{
FAMILY PROCESS WITH BREAST CANCER PATIENT IN INDONESIA
}

\author{
Sarah Kartika Wulandari*, Yanti Hermayanti*, Ahmad Yamin*, Ferry Efendi** \\ * Faculty of Nursing, Universitas Padjadjaran \\ ** Faculty of Nursing, Universitas Airlangga \\ Email: sarahwulandari88@gmail.com
}

\begin{abstract}
Introduction: Breast cancer occupies the first position in Asia's women cancer cases in recent years. Signs and symptoms experienced by the patient affect the stress condition of the patient as well as the family as a caregiver. The condition changes to deal with problems during patient assistance as a major problem in an outpatient setting. The demands of adaptation to through the needs during the period of assistance by the family is more complex. The study aimed to determine the experience of stress and adaptation of breast cancer patient's family. Methods: The qualitative method used with in-depth interviews on seven respondents who were the family caregiver of breast cancer patients. Setting carried out at the shelter house in Bandung. The analysis process used thematic analysis based on Braun \& Clarke. Results: The results found five main themes are: 1) Stressor on breast cancer patients, 2) Crisis fulfillment of companion needs, 3) Crisis accompaniment, 4) Coping mechanisms of caregiver, and 5) Ability in adaptation. Conclusions: Family experience in assisting breast cancer patients who undergo outpatient also impact families tension who traversed with a subjective effort optimally to adapt in accompanying patients and the needs of other resource support system. Suggestions for future step are early recognition of stress by health workers especially nurses to be able to provide targeted interventions to develop positive adaptation to clients. The development through research is needed in applying family center care both the outpatient and inpatient care in an integrated manner.
\end{abstract}

Keywords: adaptation, breast cancer, caregiver, stress

\section{INTRODUCTION}

The Indonesian profile in the WHO (2014) shows the statistics of cancer incidence reaching 103,100 new cases compared to new cases in the world of 14.1 million cases. Specific cases of breast cancer in West Java show an incidence of $1.0 \%$ of the population (Riskesdas) (2014). Anderson and Jakesz (2008) state that developing countries need practical, cost-effective resource interventions in the treatment of breast cancer. Hopkinson (2016) proven eating disorders often occur in cancer patients and affect the family diet until cachexia syndrome. While the family as an informal caregiver who became the primary caregiver tended to experience depression, physical \& mental fatigue (Buyck et al. (2011); Papastavrou, Charalambous, and Tsangari (2012). Limited resources in socioeconomic problems made consequence of improper treatment (Obrist et al., 2014). Especially for patients with outpatient treatment. The role of the family to be the companion not only affects the patient but also the condition of the resources around the family.

Resources for handling breast cancer include healthcare facilities, skilled health workers, and support resources including family and social. Resources that can be exploited and influential one of which is the family (Beaver, Williamson, \& Briggs, 2016). Family assistance can be a support to optimize the condition of breast cancer patients. Controlling signs \& symptoms such as fatigue, anemia, hot flashes, hair loss, impaired mobility, decreased appetite and activity intolerance (Jones, Eves, Haykowsky, Freedland, \& Mackey, 2009); Tachi et al. (2015); Tsitsis and Lavdaniti (2014) and family confusion accompanying breast cancer patients. The stressors in the treatment process will affect family status (Govina et al., 2014). Changes in family psychological conditions according to Khanjari, Langius-Ekl€of, Oskouie, and Sundberg (2014) appear at least after six months of patients diagnosed with breast cancer. Some treatment options for breast cancer include surgery, chemotherapy, radiotherapy and a combination of these therapies that have therapeutic effects as well as side effects in patients starting during preparation, during implementation and after treatment (Kumar \& Bhasker, 2015). Conditional conditions should be explored to prepare the process of treatment, especially in the outpatient care.

The healthcare process as one of the functions of the family in addition to reproductive, socializing, economic and affective functions (Kaakinen, Gedaly-Duff, Coehlo, \& Hanson, 2010) began to be developed with a team of health professionals. This is aligned with the development of family center care methods in several health facilities that want to involve families actively to 
improve the quality of services and satisfaction of clients and health workers in the treatment and care process. Family increasing caring ability showed decreasing burden and indicated a calming bereavement (K.-C. Lee, Yiin, \& Chao, 2016). It becomes important to know the condition and potential sources of family.

Based on the text above, the research aimed to determine the experience of stress and adaptation process of family who had breast cancer patients in the area of Bandung City. This study aims to know and understands the experience of stress and adaptation of family of breast cancer patients in Bandung.

\section{MATERIALS AND METHODS}

The research used the qualitative method and purposive sampling with an interview with the informal caregiver of breast cancer patients who undergo treatment and outpatient setting in Bandung. Interview guide developed by the first researcher with content validity by the second and third researcher using the middle range theory 'The Family Stress and adaptation' (Geri LoBiondo-Wood, 2008). Participants targeted using purposive sampling with inclusion criteria such as: family members of breast cancer patients who have been assisting and actively involved in care (primary caregiver) at least 6 months (Khanjari et al., 2014) to the patient since being diagnosed by the doctor, has signed informed consent at the beginning of the research, the participants are located in Bandung City. For the exclusion criteria depends on children or adolescents $(<16$ years old), participants with communication disorders and participants with mental disorders. The recruitment settled by the first researcher by visited the manager of shelter house and sorted out the participant that fit the criteria. The anonymity used initials coding to each participant. Ethical approval number 519/UN6.C10/PN/2017 by Research Ethics Commission Medical Faculty of Padjadjaran University.

The study was conducted from April to June 2017 when the saturation data was obtained through intense meetings with participants. In hence conducted the rigor and trustworthiness interview used an optimal interview from the 3-5 session, triangulation data $\&$ investigator, and peer debriefing. The time spent on interviews averaged 51 minutes. The research setting was in a shelter house called Rumah Teduh Inn located in Bandung City, West Java. Participants lived as long got some cancer medication and/or treatment where lived periodically in 4 separate houses. Specifically for this study focused on the 1st and 2 nd houses. This is because the existence of patients appropriate for inclusion criteria focused on that location. This research used indepth interview technique with tape recorder and field note assistance prepared during the interview process. Analysis of this study using thematic analysis (Braun \& Clarke, 2006).

\section{RESULTS}

This study obtained seven (7) participants who were related to their position as a caregiver/companion for breast cancer patients who underwent treatment in Bandung City. Participants consisted of six patient as husbands and one child of the patient and all of whom were men. The educational level of participants is in the range of elementary school- senior high school level. Participants have been accompanied the patient through the illness begun - now at least 6 months and a maximum of 4 years.

Table 1. Participant demographic information

\begin{tabular}{cccc}
\hline Age & Kinship & Employment status & Lengthy as caregiver \\
\hline 53 years & Husband & No job & 1 year \\
35 years & Husband & No job & 2 years \\
71 years & Husband & No job & 4 years \\
23 years & Son & No job & 7 months \\
54 years & Husband & No job & 3 years \\
44 years & Husband & No job & 2 years \\
30 years & Husband & No job & 1 year \\
\hline
\end{tabular}




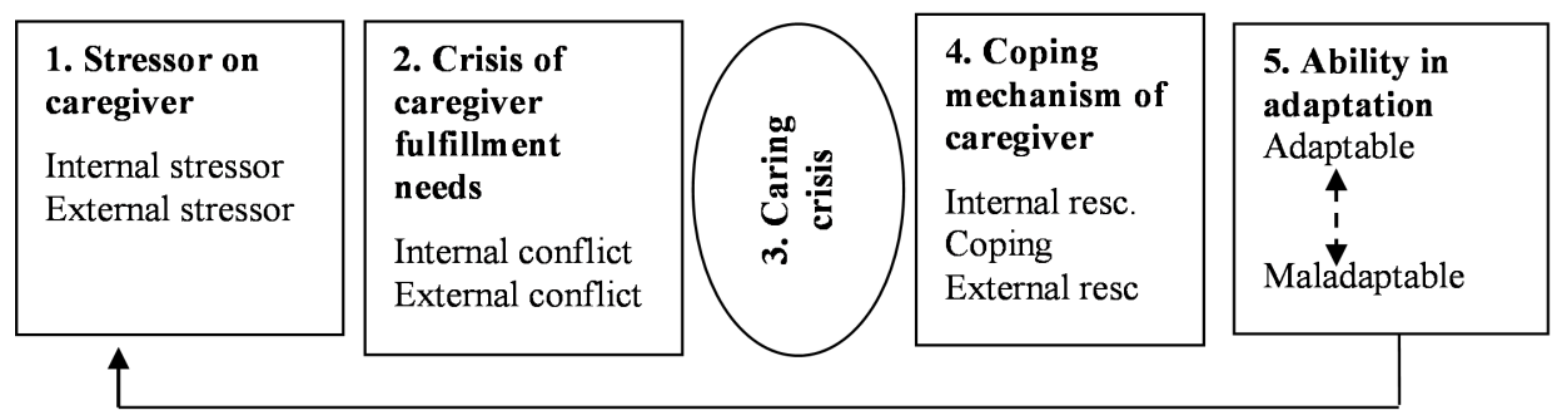

Figure 1. The themes scheme of stress and adaptation process in breast cancer caregiver

We found out five main themes: 1) Stressor on the caregiver, 2) Crisis of caregiver fulfillment needs, 3) Caring crisis, 4) Coping mechanism of caregiver, and 5) Ability in adaptation as depicted in Figure 1. The first theme, Stressor on caregiver: the demands of family problems are elaborated through sub-themes, according to delays in recognizing and managing disease; and family economic difficulties, as an internal stressor. Meanwhile, external stressors, according to assessing the limitations of patient activity, the complexity of health insurance, long treatment process, and suspicion on the surrounding community. The second theme, Crisis of caregiver fulfillment needs (reaction to internal and external impacts) is elaborated with subthemes, such as internal conflicts (changes in the family, difficulty working, physical and mental fatigue, separated grief with the nearest member of the family, conflicts of treatment decision-making). The sub-theme builds the internal tension that occurs in the family companion. Meanwhile, external conflict consists of limited assistance and support to the family, the shock of the patient's condition worsened.

Third, the conflict that occurred causing tension that manifested into the core theme of this research, namely Caring crisis. The caring crisis is described as a family stress condition in the face of unresolved problems after utilizing optimal existing resources and requiring additional resources. The crisis manifests in the form of limited economic resources (prolonged), the progressive condition of declining patients, death threats, and social environmental conditions.

Fourth, in the coping mechanism of caregiver is divided into three main components were (1) internal resources, (2) caregiver coping, and (3) external resources.
Internal resources are understood as all assets, kinship, core family support that has been optimized by the companion. While external resources consist of alternative medicine, third party, social support in patient-family, assistance from shelter home. The coping consists of trying to obey the treatment for the conviction of healed, resignation to family conditions, entrusted to professional health workers, build coping with prayer and gratitude.

In the theme adaptability capability, there are four sub-themes: additional nutrition, adaptation, pain relief, health system adjustment. Nutrition information need of patient was focusing by the caregiver for preparation in next phase of treatment (radiation and/or chemotherapy). Caregiver used pain relief as simple intervention such as massage and hot compress applied in shelter house after the treatment in hospital.

\section{DISCUSSION}

Caregiver burden in cancer patient was complex and progressive, influenced by resource conditions inside and outside the family. Factors that affected the burden condition was the available resources such as daily activities competences, education level, gender, and financial status by the caregiver (Vahidi et al., 2016). This study found that level of education of participants was a range of elementary- senior high school level and equal, the condition of economic limitations and changes in daily activities experienced by all participants whose all male. Other research by Alptekin, Gonullu, Yucel, and Yarıs (2010) stated that informal female companions are more susceptible to decreased quality of life due to being a companion of cancer patients than male counterparts. In this research, the opposite occurred when the caregiver was all 
man who was six are husband, and one is the son of the patient. In case they also feel the stress but not expressed verbally that much as they kept the pride as the head of the family. However, Jaafar et al. (2014) stated depression experienced by breast cancer patients related to ethnicity, duration of mentoring, patient functional status, and level education of caregiver. In this study participant open to all gender but because of caregiver and patient came from outside Bandung so that they prefer accompanied by the family were men or because there is no other family member as a caregiver. The other related results are described in detail in each sub-theme below.

In the sub-themes of internal stressors related to the delay in recognizing \& managing of the disease and the economic difficulties of the families that are sources of internal stressor are perceived as internal stressors arising from limited capacity of companion resources.

"Yes... that time ..delay happened. So its delay about two months. Two months finished the regular medicine I didn't get here; I was so busy with (work)" (RI)

The recognizing \& managing also delayed significantly attributable to the patient's doubt whether his disease is benign or malignant (Taib, Yip, Ibrahim, CJ, \& Farizah, 2007). Although there are also other factors such as residence distance were far away from health care facilities, marital status and the presence of children to be cared for. The financial problem tends to be the main burden of cancer patients (Vahidi et al., 2016), in line with Kaplan, Madden, Mijanovich, and Purcaro (2013) that explained of stressor in weak economic community group which one of them was overcome with helped by the coadministered funds between government and private parties (Moffat, Noble \& White, 2012). The conditions become problem associated with early treatment for breast cancer patients within the family that can lead to the quality of life of patients and caregiver (family). The financial problem becomes a stressor from the beginning until the end of the breast cancer treatment and care.

"But from me, I couldn't get it (pay by out of pocket its self). Because I work as daily worker only" (R7)
In the subtheme, the external stressor described as it 1) assessing the limitations of patient activity, 2) the complexity of health insurance, 3) lengthy treatment process, and 4) suspicion on the surrounding community. The patient's activity ability does indeed decrease during the disease process and treatment but still important to 'normalize' the patient to make sure they feel 'alive' and useful to others (Walshe et al., 2017). It certainly decreased the auxiliary load for ADL activity which is on the average increase in line with the improvement of conditions during the treatment process of the disease (Vahidi et al., 2016). Treatment time tends to be long since the diagnosis of disease has a positive correlation with the social burden and family life (Rha, Park, Song, Lee, \& Lee, 2015). In the other hand health insurance for long way treatment needed. Chongsuvivatwong et al. (2011) state that health-related insurance implemented in Indonesia with decentralization system (Swadana) in implementation still needs stabilization because of the lack of supporting infrastructure. While a lack of understanding in national health insurance coverage may contribute to treatment inadequacy (Obrist et al., 2014). Accumulation of this stressor turns into caregiver burden of the family both internally and externally which then affects the family condition to respond to overcome it.

\section{"Honestly we have (BPJS/national health insurance), but I didn't know how to use it, how the procedure....So I didn't know it before, so when it happens (illness comes) that time we knew as it is. " (R4)}

The crisis of fulfillment of caregiver needs were elaborated through the sub-themes component of the internal conflict that is 1) the change in the family, 2) the difficulty of working, tired of the physical \& mind, 3) the sadness of separation with the nearest person, and 4) the conflict of decision-making treatment. The hope for appreciated, listened and accompanied was not only happened to the patient but also on the caregiver (Kardiyudiani, 2012). Regan, Levesque, Lambert, and Kelly (2015) claimed the change in the role of the couple was an absolute matter in the condition of couples who have cancer and not infrequently the contradictions within the family or spouse in the process of disease and treatment. Role-shifting more on 
practical help in everyday activities occurred as a result. Meanwhile, for a caregiver functional change requires a qualified ability to perform several tasks with special skills, such as treating injuries, treating patients congested, pain, memorizing drug delivery patients (Regan et al., 2015). Adjustment to the condition of the patient may affect both physical and psychological companions, including sleep disturbances (Zhang, Yao, Yang, \& Zhou, 2014) as presented by Participant 1:

"Last night I couldn't sleep, so I did not sleep at all." (R1).

They felt hard to continuing their life whether the spouse must be ill every time. The other conditions of difficulty in working were more complicated problem with increased financial needs in accompanying cancer patients ultimately decrease the ability of a caregiver in full-time work (Vahidi et al., 2016). A time-consuming maintenance burden becomes a major problem that occurs in many caregivers (Govina et al., 2014). Farewell during the treatment and treatment process contributes to the burden during side-by-side treatment (Govina et al., 2015) in addition to gender, family status, education, previous caring experience, occupational status, the difficulty of care, anxiety, and depression. So that caregivers end up adjusting job options or stopping working to care for sick family members.

"Yes, I quit the job..strait away calling for my boss. Boss, I couldn't send the packet (work as courier), my wife was got sick again." (RI)

Sub-theme component in the external conflict in this research, such as 5) limited support \& support to the family, 6) shock the patient's condition worsened. The deterioration of the patient's condition results in increased emotional distress on the caregiver (Burridge, Barnett, \& Clavarino, 2009). Treatment decisions become the focus of counseling and sometimes between patients, spouses and families or relatives to differences in responding and choosing treatment options (Regan et al., 2015). Then there was the process of discussion (bargaining) in the selection of treatment. Limitations of assistance to families are linked to the growing needs of family conditions and long-term disease processes so that the needs and resources become unbalanced. The tension arises in the caregiver when creates a crisis that cannot resolve with the usual coping strategies and mechanisms (Barker, 2009); Townsend (2008). The development needed about uses resources and coping strategies additional broader than before.

Components of caregiver coping mechanism themes are elaborated with coping sub-themes covered by four topics, 1) endeavoring for a cure, 2) resignation of the family condition, 3 ) entrusting to professional health officers, and 4) building coping with prayer \& gratitude. The family entrusted the professional health staff (Walshe et al., 2017) is a key form of emotional accompaniment, practice, and social support that positively impacts the patient and accompanies the treatment. The ambiguity of resignation is perceived as the dilemma faced by the caregiver for the limitation of their ability to care for the patient with the complexity of complaints and needs to lead to emotional distress (Regan et al. (2015); Papastavrou et al. (2012). The hope of recovered (as normal) after treatment at health service delivered family to support patient in treatment (Anggraeni \& Ekowati, 2010). Sometimes This requires another self-help coping of the companion one of which holds on to the belief or belief that it has.

The sub-theme of external resources is four topics, 5) alternative medicine as treatment shortcut, 6) the third party in treatment, 7) impact of social support on patient-family, and 8) meaningful assistance from the shelter. Peer group communication is effective as one of social support apart from the community and family. This gives a different effect to the communication experience with the professional staff. Because they learn from those, who experience the same thing as they share strategies to get through the problem (Walshe et al., 2017). The use of other treatment options such as traditional and alternative is still the most favorite in breast cancer patients such as Kota Bharu, Malaysia (Taib et al., 2007) who are still both Malay with Indonesia. The reasons for its use are various, ranging from operating fears, friend influences, possible treatment success beliefs, and bad experiences in previous hospitals. A comparison of both countries showed that cancer patients in 
Indonesia attacked the younger age group $(<48$ years) with a higher cancer stage in Indonesia than Malaysia (Ng et al., 2011).

"Alternative medicine advise came
from our neighbor. They said
alternative could do it (healing)
without operation." (R7)

Other resources that need to be developed for further access was the shelter service. Shelter service as the temporary place is managed by government and private sector through empowerment of government accredited foundation in Indonesia. The results of other health care facilities resemble as the study by Y. S. Lee et al. (2017) suggest that care at the hospice indicates a decrease in hospital admission rate, the comfort of living with a companion, active visits from doctors and nurses optimizing end of life care. So this contributes to late checks and treatment into a problem that can increase the burden of health in Indonesia and requires coping and management strategies of the participants and all parties involved.

Developing trust implemented by the form of praying and developing hope was done as a form of self-support in dealing with problems based on the value of spirituality that is believed (Anggraeni \& Ekowati, 2010). Although other studies show avoidance behavior and rejection are still significantly occurring as coping with higher levels of depression of facilitation (Papastavrou et al., 2012). Mostly the caregiver in this research again built trust submit to fate and praying as once of coping mechanism.

Components of themes of adaptability found four topics, 1) additional nutrition efforts, 2) adapt to each other, 3) help with pain and 4) adjustment to the health system. Information on nutrition is one of the main information needed by patients other than disease management information (Kamiafar, Sarbaz, Sales, \& Esmaeili, 2016). This information is not only the patient but also required by the companion. This is because the provision of nutrients will be further diverted to the task of caregiver especially in the condition of outpatients as in this study. Caregiver education programs are proven effective in improving the quality of life of patients with topics of food support, care services, welfare services (massage), and symptomatic management (Belgacem et al.,
2013). Adjustment to the health system is a form of adaptation developed by a companion to succeed the patient's smooth treatment. In this process is not uncommon caregiver experience obstacles and confusion when told the procedure to be passed for patients get treatment (Anggraeni \& Ekowati, 2010). This certainly hampers the process of health care assistance by the family.

Family health care in this study is based on Theory of Family Stress and Adaptation (G. LoBiondo-Wood, 2008) which is the middle-range theory group. Components of the theory are synergistic with the concept of the nursing paradigm that has four components: human, health, environment and nursing (Potter \& Perry, 2010). The nursing approach is more focused on the individual (client) and the environment is not a disease according to the nursing concept assumption F. Nightingale (Parker \& Smith, 2010) in harmony with Theory of Family Stress and Adaptation (LoBiondo-Wood, 2008). So the results of the study are expected to be in line with the philosophy of nursing.

Regan et al. (2015) addressed the themes of response to cancer, how to deal with cancer, experience with health workers, and transition to survivorship status. Compared to this study, we describe the components according to the setting of the shelter house in the process and the time span that marks the mentoring process in the care of cancer patients. Travel assistance of cancer patients through the mechanism of action - long-term reaction. Response to cancer, elaborated through a stress process divided into primary stressors (direct effects) and secondary (side effects), perceptions of the condition that is individual that builds self-efficacy. This has an impact on how to address the mentoring process in the course of the disease (Fletcher, Miaskowski, Given, \& Schumacher, 2012). The emerging crisis results from the inability to cope with existing problems with family coping mechanisms normally used (Barker, 2009). To develop other coping mechanisms with additional resources that exist around to achieve balance and adaptation.

\section{CONCLUSIONS}

The conclusion of this research is the experience of stress and adaptation of the family of breast cancer patient in Bandung is a 
continuous stage of the stressor to the formation of crisis that requires continued coping until the formation of adaptation by the breast cancer patient. This continuous process is evident in the themes gained through research on participant experience as a companion. Support from professional nurses may be needed to minimize the stress and pass on the adaptation process.

\section{Acknowledgment}

Our appreciation goes to all caregivers and patients and NGO who help each other to combat cancer out there. The research supported by a scholarship from The Education and Cultural Ministry of Indonesia.

\section{REFERENCES}

Riskesdas (2014). Profil Kesehatan Provinsi Jawa Barat Tahun 2014. Indonesia: Dinas Kesehatan Provinsi Jawa Barat.

Alptekin, S., Gonullu, G., Yucel, I., \& Yarıs, F. (2010). Characteristics and quality of life analysis of caregivers of cancer patients. Medical Oncology, 27, 607617. doi: DOI 10.1007/s12032-0099256-2

Anderson, B., \& Jakesz, R. (2008). Breast Cancer Issues in Developing Countries: An Overview of the Breast Health Global Initiative. World Journal of Surgery, 32, 2578-2585. doi: $10.1007 / \mathrm{s} 00268-007-9454-\mathrm{z}$

Anggraeni, M., \& Ekowati, W. (2010). Peran keluarga dalam memberikan dukungan terhadap pencapaian integritas diri pasien kanker payudara post radikal mastektomi. The Soedirman Journal of Nursing, 5(2), 105-114.

Barker, P. (2009). Psychiatric and mental health nursing: The craft of caring (2 ed.). London-UK: Hodder Arnold (Publishers) Ltd.

Beaver, K., Williamson, S., \& Briggs, J. (2016). Exploring patient experiences of neo-adjuvant chemotherapy for breast cancer. European Journal of Oncology Nursing, 20(1), 77-86. doi: http://dx.doi.org/10.1016/j.ejon.2015.0 $\underline{6.001}$

Belgacem, B., Auclair, C., Fedor, M.-C., Brugnon, D., Blanquet, M., Tournilhac, O., \& Gerbaud, L. (2013). A caregiver educational program improves quality of life and burden for cancer patients and their caregivers: A randomised clinical trial. European Journal of Oncology Nursing, 2013, 17. doi: http://dx.doi.org/10.1016/j.ejon.2013.0 $\underline{4.006}$

Braun, V., \& Clarke, V. (2006). Using thematic analysis in psychology. Qualitative Research in Psychology, 3, 77-101. doi: 10.1191/1478088706qp063oa

Burridge, L. H., Barnett, A. G., \& Clavarino, A. M. (2009). The impact of perceived stage of cancer on caregivers' anxiety and depression during the patients' final year of life. Psycho-Oncology, 18, 615-623. doi: 10.1002/pon.1435

Buyck, J.-F. M. D. M., Bonnaud, S. M., Boumendil, A. P., Andrieu, S. M. D. P., Bonenfant, S. M., Goldberg, M. M. D. P., . . Ankri, J. M. D. P. (2011). Informal Caregiving and SelfReported Mental and Physical Health: Results From the Gazel Cohort Study. American Journal of Public Health, 101(10), 1971-1979.

Chongsuvivatwong, V., Phua, K. H., Yap, M. T., Pocock, N. S., Hashim, J. H., Chhem, R., . . Lopez, A. D. (2011). Health and health-care systems in southeast Asia: diversity and transitions. Lancet, 377, 429-437. doi: DOI:10.1016/S0140-6736(10)61507-3

Fletcher, B. S., Miaskowski, C., Given, B., \& Schumacher, K. (2012). The cancer family caregiving experience: An updated and expanded conceptual model. European Journal of Oncology Nursing, $\quad 16, \quad 387-398 . \quad$ doi: 10.1016/j.ejon.2011.09.001

Govina, O., Kotronoulas, G., Mystakidou, K., Katsaragakis, S., Vlachou, E., \& Patiraki, E. (2015). Effects of patient and personal demographic, clinical and psychosocial characteristics on the burden of family members caring for patients with advanced cancer in Greece. European Journal of Oncology Nursing, 19, 81-88. doi: http://dx.doi.org/10.1016/j.ejon.2014.0 $\underline{6.009}$

Govina, O., Vlachou, E., Kavga-Paltoglou, A., Kalemikerakis, I., Papageorgiou, D., Fasoi, G., \& Patiraki, E. (2014). 
Exploring the factors influencing time and difficulty of tasks provided by family caregivers of patients with advanced cancer in Greece. Health Science Journal, 8(4), 438-451.

Hopkinson, J. B. (2016). Food connections: A qualitative exploratory study of weight- and eating-related distress in families affected by advanced cancer European Journal of Oncology Nursing, 20, 87-96. doi: http://dx.doi.org/10.1016/j.ejon.2015.0 $\underline{6.002}$

Jaafar, N. R. N., Din, S. H. S., Saini, S. M., Ahmad, S. N. A., Midin, M., Sidi, H., . . . Baharudin, A. (2014). Clinical depression while caring for loved ones with breast cancer. Comprehensive Psychiatry, 55, S52-S59. doi: http://dx.doi.org/10.1016/j.comppsych .2013 .03 .003

Jones, L. W., Eves, N. D., Haykowsky, M., Freedland, S. J., \& Mackey, J. R. (2009). Exercise intolerance in cancer and the role of exercise therapy to reverse dysfunction. The Lancet Oncology, 10, 598-605. doi: http://dx.doi.org/10.1016/S14702045(09)70031-2

Kaakinen, J. R., Gedaly-Duff, V., Coehlo, D. P., \& Hanson, S. M. H. (2010). Family health care nursing : theory, practice, and research (4th ed.). United States of America: F. A. Davis Company.

Kaplan, S. A., Madden, V. P., Mijanovich, T., \& Purcaro, E. (2013). The Perception of Stress and its Impact on Health in Poor Communities. Journal of Community Health, 38(1), 142-149. doi: http://dx.doi.org/10.1007/s10900012-9593-5

Kardiyudiani, N. K. (2012). Phenomenology Study; Hope of breast cancer patients who have chemotherapy about family support in cancer Dharmais Hospital Jakarta. (Master), University of Indonesia, Jakarta-Indonesia.

Khanjari, S., Langius-Ekl€of, A., Oskouie, F., \& Sundberg, K. (2014). Family caregivers of women with breast cancer in Iran report high psychological impact six months after diagnosis. European Journal of Oncology Nursing, 1-6. doi: http://dx.doi.org/10.1016/j.ejon.2014.0 $\underline{6.002}$

Kumar, R. V., \& Bhasker, S. (2015). Healthcare related supportive-care factors may be responsible for poorer survival of cancer patients in developing countries. Journal of Cancer Policy, 5, 31-47. doi: http://dx.doi.org/10.1016/j.jcpo.2015.0 $\underline{5.002}$

Lee, K.-C., Yiin, J.-J., \& Chao, Y.-F. (2016). Effect of integrated caregiver support on caregiver burden for people taking care of people with cancer at the end of life:

A cohort and quasi-experimental clinical trial. International Journal of Nursing Studies, 56, 17-26. doi: http://dx.doi.org/10.1016/j.ijnurstu.20 $\underline{16.01 .002}$

Lee, Y. S., Akhileswaran, R., Hock, M. O. E., Wah, W., Hui, D., Ng, S. H.-X., \& Koh, G. (2017). Clinical and sociodemographic predictors of home hospice patients dying at home: A retrospective analysis of Hospice Care Association's database in Singapore. Journal of Pain and Symptom Management, 2017. doi: 10.1016/j.jpainsymman.2017.01.008

LoBiondo-Wood, G. (2008). Theory of Family Stress and Adaptation. In M. J. Smith \& P. R. Liehr (Eds.), Middle range theory of nursing (2 ed., pp. 225-238). United State of America: Springer Publishing Company, LLC.

LoBiondo-Wood, G. (2008). Theory of Family Stress and Adaptation Middle Range Theory fo Nursing (2 ed.). New York, USA: Springer Publishing Company, LLC.

Moffatt, S., Noble, E., \& White, M. (2012). Addressing the Financial Consequences of Cancer: Qualitative Evaluation of a Welfare Rights Advice Service. PLoS One, 7(8). doi: 10.1371/journal.pone.0042979

http://dx.doi.org/10.1371/journal.pone. 0042979

Ng, C., Pathy, N. B., Taib, N., Teh, Y., Mun, K., Amiruddin, A., . . Y Yip, C. (2011). Comparison of Breast Cancer in Indonesia and Malaysia - A ClinicoPathological Study Between Dharmais Cancer Centre Jakarta and University 
Malaya Medical Centre, Kuala Lumpur. Asian Pacific Journal of Cancer Prevention, 12, 2943-2946.

Obrist, M., Osei-Bonsu, E., Ahwah, B., Watanabe-Galloway, S., Merajver, S. D., Schmid, K., \& Soliman, A. S. (2014). Factors Related to Incomplete Treatment of Breast Cancer in Kumasi, Ghana. Breast, 23(6), 821828. doi: 10.1016/j.breast.2014.08.014

Papastavrou, E., Charalambous, A., \& Tsangari, H. (2012). How do informal caregivers of patients with cancer cope: A descriptive study of the coping strategies employed. European Journal of Oncology Nursing, 16(1), $258 \mathrm{e} 263$. doi: doi:10.1016/j.ejon.2011.06.001

Parker, M., \& Smith, M. C. (2010). Nursing theories and nursing practice (3 ed.). USA: F.A. Davis Company.

Potter, P. A., \& Perry, A. G. (2010). Fundamental Keperawatan (7 ed.). Jakarta: Salemba Medika.

Regan, T., Levesque, J. V., Lambert, S. D., \& Kelly, B. (2015). A Qualitative Investigation of Health Care Professionals', Patients' and Partners' Views on Psychosocial Issues and Related Interventions for Couples Coping with Cancer. PLoS One, 10(7). doi: $\quad 10.1371$ journal.pone.0133837 http://dx.doi.org/10.1371/journal.pone. $\underline{0133837}$

Rha, S. Y., Park, Y., Song, S. K., Lee, C. E., \& Lee, J. (2015). Caregiving burden and the quality of life of family caregivers of cancer patients: the relationship and correlates. European Journal of Oncology Nursing, 2015, 1-7. doi: http://dx.doi.org/10.1016/j.ejon.2015.0 $\underline{1.004}$

Tachi, T., Teramachi, H., Tanaka, K., Asano, S., Osawa, T., Kawashima, A., . . . Goto, C. (2015). The Impact of Outpatient Chemotherapy-Related Adverse Events on the Quality of Life of Breast Cancer Patients. PLoS One,
10(4).

doi:

10.1371/journal.pone.0124169

http://dx.doi.org/10.1371/journal.pone. $\underline{0124169}$

Taib, N. A., Yip, C. H., Ibrahim, M., CJ, N., \& Farizah, H. (2007). Breast Cancer in Malaysia : Are Our Women Getting The Right Message? 10 YearExperience in A Single Institution In Malaysia. Asian Pacific Journal of Cancer Prevention, 8, 141-145.

Townsend, M. (2008). Essentials of psychiatric mental health nursing (4 ed.). USA: F. A. Davis Company.

Tsitsis, N., \& Lavdaniti, M. (2014). Quality of Life in Women with Breast Cancer. International Journal of Caring Sciences, 7(1), 38-42.

Vahidi, M., Mahdavi, N., Asghari, E., Ebrahimi, H., Ziaei, J. E., Hosseinzadeh, M., . . Kermani, I. A. (2016). Other Side of Breast Cancer: Factors Associated with Caregiver Burden. Asian Nursing Research, 10, 201-206. doi: http://dx.doi.org/10.1016/j.anr.2016.0 $\underline{6.002}$

Walshe, C., Roberts, D., Appleton, L., Calman, L., Large, P., LloydWilliams, M., \& Grande, G. (2017). Coping Well with Advanced Cancer: A Serial Qualitative Interview Study with Patients and Family Caregivers. PLoS One, 12(1). doi: 10.1371/journal.pone.0169071http://d x.doi.org/10.1371/journal.pone. 01690 71

WHO. (2014). Indonesia World Health Organization- Cancer Country Profiles (Vol. 2014): WHO.

Zhang, Q., Yao, D., Yang, J., \& Zhou, Y. (2014). Factors Influencing Sleep Disturbances among Spouse Caregivers of Cancer Patients in Northeast China. PLoS One, 9(10). doi: $\quad$ 10.1371/journal.pone.0108614 http://dx.doi.org/10.1371/journal.pone. $\underline{0108614}$ 